\title{
Women or Leaders? Practices of Narrating the United Nations as a Gendered Institution
}

Ingvild Bode

Accepted for publication in International Studies Review (5 December 2018)

The United Nations has been an important forum for promoting women's rights, but women are still underrepresented at the most senior levels of its leadership. This points to persistent obstacles in reaching gender parity at the $U N$, despite the organization's overt commitment to this objective. Situated in feminist institutionalist insights, I argue that the institutionalization of gender inequality through practices in the UN as a gendered institution can account for continued barriers to women leadership. This makes contributions to feminist institutionalist literature in International Relations by taking it to the individual, micro level. Practices sustain, inform, and manifest themselves in four interconnected, gendered processes that reinforce gendered divisions of subordination: positional divides, symbols and imagery, everyday interactions, and individual identity (based on Acker 1990, 146-7; Scott 1986). These processes and their practices become accessible through the narrative analysis of semi-structured interviews conducted with senior women leaders at the UN. By recognizing their narratives as valid forms of insight into the study of the UN, this approach recognizes women leaders' agency as opposed to portraying them as numbers only.

Keywords: feminist institutionalism; United Nations (UN); practices; women; gender; narratives; leadership

On December 13, 2016, an exhibition entitled "Her Story: A Celebration of Leading Women in the United Nations" opened at the UN headquarters in New York. Designed to showcase the contributions of women leaders throughout the world organization's history, it included for example Margaret Anstee, the first woman to be appointed Special Representative of the Secretary-General in a peacekeeping 
operation (in 1992). While this points to the important roles women have played throughout the UN's history, their contributions have seldom received scholarly attention. This may be because numbers of women leaders at the UN Secretariat and across the organization's other principal organs were long eclipsed by numbers of male leaders. But the pervasive lack of attention to women leaders in major international organizations such as the UN also echoes the feminist characterization of international politics as 'a man's world': "women have rarely been portrayed as actors on the stage of international politics" (Tickner 1992, xi). This contrasts sharply with a prominent image of the UN as an important political forum women's organizations have used to advance global standards of gender equality (McCarthy and Southern 2017, 27; Jain 2005, 2017; Skard 2008). Likewise, both former UN Secretary-General Ban (2006-2016) and current Secretary-General Guterres (2017-) sought to achieve gender parity in the organization's senior leadership during their tenures (Landgren 2015; Global Peace Operations Review 2017). But women continue to be underrepresented at the UN's highest echelons: they only make up $26.8 \%$ of all Assistant Secretaries-General and Under Secretaries-Generals (UN General Assembly 2017c).

These observations provide the backdrop to the puzzle inspiring this article: how is it possible that even mere gender parity continues to evade the UN's senior management despite the organization's proclaimed commitment to act? We may cynically consider these proclamations as rhetorical lip service rather than an actual desire for deeper institutional change. Further, senior UN appointments are often caught up in wider political dynamics among the UN membership. However, from a feminist institutionalist perspective, these observations point to profound hierarchical structures in the UN as a gendered institution. While gender is understood as "a set of culturally shaped and defined characteristics associated with masculinity and femininity" (Tickner 1992, 7), the process of gendering concerns "the distribution of power and regard based on perceived association with sex-based characteristics" (Sjoberg 2011, 110). An organization is gendered in "that constructions of masculinity and femininity are intertwined in (its) daily life or logic" (Mackay, Kenny, and Chappell 2010a, 580). Such hierarchical structures sustain 
gender inequality and can account for barriers to senior women leadership in the UN.

Feminist institutionalism has developed into an influential theoretical agenda to analyze the workings of gender in formal and informal political institutions, in particular at the domestic level (e.g. Acker 1992; Chappell and Waylen 2013; Kenny 2007; Hawkesworth 2003). This agenda offers innovative accounts of the power structures that actors within institutions find themselves nested in, of institutional change or continuity, and of dynamic relationships between agency and structure (Mackay, Kenny, and Chappell 2010a; Paxton and Hughes 2017, 29-30). Scholars have thus used feminist institutionalist insights to offer novel readings of organizations such as the European Union (Haastrup and Kenny 2016; Haastrup 2018; Deiana and McDonagh 2018; Ansorg and Haastrup 2018; Huelss 2017; Muehlenhoff 2017) and the UN, especially in relation to the women, peace and security agenda (Thomson 2018; Heathcote 2018; Shepherd 2008, 2011; Kaufman 2013; Ní Aoláin, Haynes, and Cahn 2011; Charlesworth 1994; Gibbings 2011; Den Boer and Bode 2018).

But this theoretical program has so far not been applied comprehensively to understand the persistent under-representation of women in positions of senior leadership at the UN. In doing this, the article analyzes how endogenous factors, such as gendered power relations, are embedded in the institutional functioning of the UN Secretariat (Mackay, Kenny, and Chappell 2010a, 582; Kenny 2007) and can help us in understanding the continued lack of gendered parity.

In considering these endogenous factors, the article focuses on how gendered power relations emerge, are sustained and resisted in practices, referring to the everyday activities of 'real women' who work in the UN Secretariat (Haastrup 2018, 583; Schmidt 2010). I explore these practices through examining five interviews with women in positions of senior leadership at the UN as narratives. The narrative form can explicate existing practices and the power relations they sustain, while also drawing attention to women's agency, thereby "putting the spotlight on women as competent actors" (Reinharz 1992, 248).

This small-scale, qualitative approach adds an individual, micro level of analysis to often quantitative studies examining continued barriers to women reaching 
leadership positions (e.g. Cook and Glass 2014; Gould, Kulik, and Sardeshmukh 2018; Ryan et al. 2016; Fritz and van Knippenberg 2018; Haack 2017) or how gendered power relations work to constrain women executives once in office (Burns and Kattleman 2017; Koch and Fulton 2011; Paxton and Hughes 2017). The latter group of studies highlights phenomena such as the double bind: women simultaneously have to perform leadership qualities primarily associated with particular notions of masculinity and act in accordance with gendered notions of 'appropriate' feminine behavior (Burns and Kattleman 2017, 23). This puts women leaders into practically impossible positions. The article's individual-level approach to examining practices within the UN as a gendered institution also complements descriptive statistical studies mapping the slow numerical rise of women in UN leadership positions (Haack 2014a, 2014b; Pietila 1996).

Feminist International Relations (IR) scholars have long been interested in highlighting how institutions can be built on and reproduce assumptions about gender through practices (e.g. True 2010, 197; Steans 2013, 3) that may, for example, constitute competence as associated with masculine qualities. Defined as patterned actions in social context (Leander 2008, 18), focusing on practices allows researchers to study how constructions are made, reified or change at the micro level. This puts the processes sustaining and constituting international relations into the center of analytical attention (Bode 2018a).

The article proceeds by offering an analytical framework for examining practices of gender inequality in the UN Secretariat as a formal institution. First, I build on the analytical work of feminist institutionalist scholars Acker and Scott in mapping four interconnected processes through which practices of gender sustain, inform and manifest themselves at the UN and thereby reinforce gendered divisions of subordination: positional divisions, symbols and imagery, everyday interactions, and individual identity (based on Acker 1990, 146-47; Scott 1986).

Second, I argue that we can access practices constitutive of gender within these processes through considering the experiences of (senior) women leaders, gained via interviews, as narratives. This approach speaks to what Zalewski calls "looking for 'the barely visible', yet solidly felt" $(2006,53)$. Narratives are themselves a practice: they are forms of human sense making through which actors, in this case women 
leaders, express their understanding of social situations and settings (Wibben 2011, 100; Suganami 1999a, 381). Studying gendered practices as they emerge in women's narratives invites nuanced understandings (Harel-Shalev and Daphna-Tekoah 2016). Instead of searching for generalizable answers, this interpretive framework approaches the effects gendered practices appear to have on particular women exercising leadership functions in the UN. This interpretive model is designed to create space for novel inductive insights. While I write in response to questions of continued gender imbalance among the senior leadership at the UN Secretariat, the model's analytical origin in wider feminist institutionalism supports its potential application to understanding similar processes across the UN system and beyond it. The remainder of the article is structured as follows: first, I develop how practices at the UN as a gendered institution can help us to understand the problem of consistent gender imbalance at high levels of leadership in more detail. Second, I provide methodological comments on the five semi-structured interview narratives with senior women leaders in the UN Secretariat. This group represents half of the ten New York-based senior women leaders in office in March-April 2014 (the time of the interviews), all of whom I approached via email. ${ }^{1}$ Third, in an empirical section, I analyze their narrative insights. Finally, I conclude with remarks about the potential and challenges of small-scale qualitative work for studying gender imbalance at the UN, as well as with avenues for further research.

\section{Gender inequality at the UN: Feminist institutionalism and practices}

Senior women leaders at the UN Secretariat continue to spend their days in environments dominated by men (Acker 1990, 139). This entails perceiving senior male leaders as 'normal' and connecting key traits of leadership with masculine characteristics, thereby making female leadership "virtually inconceivable" (Goetz 2016b). Feminist scholars have studied this association of masculinity and politics and, in particular, how positive value has been assigned to masculine qualities: “(...)

\footnotetext{
${ }^{1}$ I understand senior women leaders' as women in the most senior bureaucratic UN positions: Assistant-Secretaries-General and Under-Secretaries-General. I have chosen these levels as women are most underrepresented at these most senior positions of leadership. The title of this article aims to capture the underrepresentation of women at these levels as well as how the categories of 'women' and 'leader' continue to be captured as mutually exclusive (see also Sinclair 2005, 93-94).
} 
power, autonomy, rationality, activity and public are stereotypically associated with masculinity; their opposites - weakness, dependence/connection, emotionality, passivity, and private - are associated with femininity" (Tickner 2006, 15). Cohn illustrates this expertly in her much-cited analysis of masculinized rationality and objectivity among defense intellectuals (1987). Research has thus investigated how gender bias and stereotypes contain deep-seated status beliefs that attribute greater competence and leadership qualities with men rather than women (Ridgeway 2001). This system culminates in hegemonic masculinity (Connell 1995), a socially constructed ideal type of masculinity that does not correspond to lived reality but subordinates diverse femininities and masculinities in the service of patriarchal political order (Tickner 1992, 6).

These relationships of power and subordination work in what feminist institutionalists call gendered institutions, "arena(s) in which widely disseminated cultural images of gender are invented and reproduced" (Acker 1990, 140). Acker refers to domestic settings instead of the multi-cultural and -national work environments provided by international organizations such as the UN. Yet, socially constructed binaries around gender appear to transcend cultural boundaries (Acker $1990,145)$.

Over the last 10 years, scholars of feminist institutionalism have systematized these theoretical assumptions into an analytical program situated within the new institutionalism and designed for the study of both formal and informal institutions, often defined as "the rules of the game in a society or (...) the humanely devised constraints that shape human interaction" (North 1990, 3). In this context, the UN Secretariat encompasses a range of formal institutions, for example written-down policies and guidance, but also informal rules, norms and practices. Following feminist institutionalism, gendered power relations are part of the UN across "different institutional levels, ranging from the symbolic level to the 'seemingly trivial' level of interpersonal day-to-day interaction, where the continuous performance of gender takes place" (Mackay, Kenny, and Chappell 2010a, 580). How gender is performed in the everyday encourages a qualitative, individual-level study, which I will investigate via practices. 
Increasingly, feminist institutionalist research has also found its way into IR literature, in particular through works on international organizations such as the EU, the UN, and NATO. Here, scholars have demonstrated how analytically accounting for the gendered nature of these institutions can help us understand unintended and unimagined consequences of deeply political (implementation) processes (Haastrup 2018; Thomson 2018; Wright 2016; Wright and Guerrina 2016; Gizelis and Olsson 2015; Hurley 2018).

Building on this literature, I argue that understanding the UN as a gendered institution can provide novel answers to persistent questions about continued gender imbalance among senior leadership. In particular, I argue that we should look towards how gendered institutions work in the everyday through considering practices. Practices are patterned actions in social context (Leander 2008, 18). Examining them at the micro level makes visible what sustains international relations, for example power relations.

Feminist scholars consider gender itself a performance fed by often unconscious yet influential and wide-ranging practices (Shepherd 2010, 4). In this, practices conceptually combine reflective and reflexive qualities (Ralph and Gifkins 2017; Bode and Karlsrud 2018). They are reflective in that actors performing practices deliberately react to specific situations in recurring on what they perceive to be appropriate knowledge (Bode 2018b). They are reflexive in actualizing forms of "background knowledge" that actors are often not able to consciously draw from (Pouliot 2008, 2016; Bueger and Gadinger 2015).

Considering how women leaders engage in both reflective and reflexive practices allows me to study how notions of gender are produced, sustained, and challenged within the UN at the micro level. In this, taking reflective and reflexive practices into account speaks to and balances agency and structure questions that have perennially been at the heart of various institutionalisms (Lovenduski 2015, ix; Mackay, Kenny, and Chappell 2010a, 578, 582-83). Women leaders can reflectively deliberate on their roles in the UN and how they are situated within gendered hierarchies. But they are also exposed to and embedded within gendered institutional structures, which leads them to build up reflexive, background knowledge effectively sustaining gendered divisions. This echoes how Cohn's 
growing familiarity with the world and language of defense intellectuals lead to a certain cooptation in terms of her language and, I would add, her practices:

(...) what had once been remarkable became unnoticeable. As I learned to speak, my perspective changed. I no longer stood outside the impermeable wall of technostrategic language, and once inside, I could no longer see it. Speaking the language, I could no longer hear it. And once inside its protective walls, I began to find it difficult to get out (Cohn 1987, 712-13).

In particular, I argue that reflective and reflexive practices on gender (subordination) sustain, manifest, and inform themselves in relation to four interconnected processes, which are inspired by early theoretical work on gendered institutions (Acker 1990, 146-47; Scott 1986): positional divisions, symbols, everyday interactions, and gendered components of identity. While not providing a complete picture of how gender inequality is sustained at the UN, these four processes allow me to trace practices within them at different levels.

First, practices constitute gendered positional divisions in international organizations, that is men occupying more positions of higher organizational power or higher perceived organizational importance. Traditionally, IR distinguished between so-called high politics, associated with 'more important' security concerns, and low politics, associated with 'less vital' welfare concerns (see Haack 2014a, 4849). Attributing importance is often combined with gender subordination: 'low politics' such as education or labor are regarded as appropriate issues for women to deal with, while 'high politics' such as military and foreign policy are in turn inappropriate (Paxton and Hughes 2017, 26-27). This leads to questions concerning women's authenticity as leaders in 'high politics' portfolios: “We are socialized into believing that war and power politics are spheres of activity with which men have a special affinity and that their voices in describing and prescribing for this world are therefore more authentic" (Tickner 1992, 4-5; see also Koch and Fulton 2011; Burns and Kattleman 2017; Cotter-Lockard 2017). Senior women leaders in the UN Secretariat are often found in "portfolios that are considered gender appropriate," such as education, welfare and the environment (Haack 2014a, 48). Men have exclusively occupied the major diplomatic or technical posts that the UN Secretariat 
offers - such as the UN Secretary-General, the Under-Secretary-General for Political Affairs, and the Under-Secretary-General for Peacekeeping.

The 2016 appointment process for the UN Secretary-General illustrates these gendered positional divides (Bode 2017). Calls for a female Secretary-General were heard loud and clear, especially during the most transparent appointment process ever for the UN. The 13 candidates featured seven highly qualified women, who were voted on with the male candidates in six secret straw polls conducted by the 15 UN Security Council members, 14 of which were represented by men. Interestingly, female candidates almost across the board ranked lower than their male counterparts in the straw polls (Goetz 2016a). As Mogens Lykketoft, the UN General Assembly president at the time, reflected in December 2016: "If anyone can handle this seemingly impossible role at this point in time, it is António Guterres" (Holm and Lykketoft 2017). Notwithstanding Guterres' track record of significant relevant expertise, practices surrounding proclamations of his 'unique' suitability for the position underline and reproduce gendered positional divides at the very heart of the UN.

Second, symbols may reinforce and sustain gendered divisions, for example the use of particular language or linking certain leadership skills with constructed qualities of masculinity such as "a tough-minded approach to problems; (...) a capacity to set aside personal, emotional considerations in the interests of task accomplishment" (Moss Kanter 1975, 43). Gendered images of masculinity and femininity become embedded within organizational structures as "prototypical symbols" (Elshtain 1995, 6), constitutive of how women leaders perceive of themselves and are perceived of by others. Pointers to these practices can be found in examining to what extent portrayals of 'successful' women leaders are influenced by whether they behave in a "gender-appropriate" manner (see Shepherd 2010, 12) or are perceived as "masculinized" (e.g. Kawakami, White, and Langer 2000; Koch and Fulton 2011; Burns and Kattleman 2017).

Third, one can identify everyday interactions that enact gendered divisions. This everyday quality is an important component of practices. We should not expect gender practices to manifest in 'dramatic moments' only, although the 2015 Secretary-General selection process provided an opportunity to do just that. But 
practices function in mundane, everyday ways, which can make them hard to analyze. Yet, it is precisely here that 'acceptable' and 'inacceptable' displays of femininity and masculinity are negotiated (Zalewski 2010, 33).

Fourth, gender seeps into how women leaders understand and see themselves and becomes part of practices associated with gendered components of individual identity. The simple fact that gendered practices are constitutive of people's identities is what makes these constructions so powerful: "gender is something that we do, or how we perform our identities in day-to-day life" (Steans 2013, 29). Yet, people's identities are inherently complex and plural, they are the products of diverse socialization processes, manifesting themselves in different practices across specific situations (Lahire 2011). This also acknowledges that gender is only one set of hierarchical power relations that women leaders may be subject to. Women leaders may therefore represent themselves and the gendered parts of their identity in various different ways (Harel-Shalev and Daphna-Tekoah 2016, 186) and in that conform or confound conventional gender practices.

In summary, I argued that understanding practices at the UN as a gendered institution allows us to analyze how gender inequality affects women leadership in the UN Secretariat. Based on work by feminist institutionalist scholars Acker and Scott, I argue that gender practices manifest themselves in four inter-connected processes: gendered positional divisions, symbols and imagery, everyday interactions, and gendered components of individual identity. In focusing on practices contained in these processes, we can visualize how gender inequality maintains itself in organizational settings. To get to these practices, I suggest engaging in an interpretive, narrative analysis of interviews with women leaders.

\section{Gender practices at the UN: A narrative methodology}

Accessing practices presents theorists with empirical challenges as they rarely become visible via established qualitative methods such as document analysis alone (e.g. Bueger 2014). I argue that we can render such practices visible through studying the experiences of women leaders at the UN Secretariat as narratives. The narratives of individual women leaders in their places of work can speak to the “interplay of personal, local, national, and international dynamics" (Enloe 2010, xvii), 
while maintaining the specificity and particularity of women leaders' experiences (Steans 2013, 26).

Narratives have long occupied a prominent place in feminist IR (Enloe 2014; Shepherd 2013; Sylvester 2013; Wibben 2011). The narrative is a particular form of practice that is intimately connected to human ways of sense-, meaning- and ultimately knowledge-making (Wibben 2011, 100; Suganami 1999a, 381; Bode 2015, 47). Following Suganami's definition: "stories or narratives are an instrument of comprehension (...) by means of which we express our understanding of a given set of events and/or acts, (...) to ourselves and to others, thereby necessarily producing an explanation of it" (1999b, 344). Narratives therefore allow us to access how actors make sense of their realities through narrating and how they figure themselves as characters in their stories.

Studying gendered practices in the UN system as they emerge in women leaders' narratives also avoids portraying these practices in oversimplified and generalized categories. Instead, both women's experiences and how they make gendered practices visible are analyzed with nuance (Harel-Shalev and Daphna-Tekoah 2016, 173). My interpretive methodology is explicitly inspired by Harel-Shalev and DaphnaTekoah's (2016) work on narrative. Therefore, I do not aim to develop generalisable answers to the empirical puzzle I identified, but rather to provide nuanced understandings of practices sustaining this puzzle. I do this by mapping how individual women leaders experience gendered practices in their day-to-day lives and what kind of effect they appear to have on women exercising leadership functions.

The article approaches these narratives using transcripts from five semi-structured interviews with senior women leaders I conducted in March-April 2014. ${ }^{2}$ At the time, all interviewees served in senior leadership positions at the UN Secretariat. ${ }^{3}$ They represent a variety of core UN issue-areas and vary in their nationalities ${ }^{4}$ and career

\footnotetext{
2 Interviews were between 45 minutes and 1 hour in length.

3 I approached all ten New York-based senior women leaders in office at the time of the interviews and five women responded positively.

${ }^{4}$ The five interviewees have five different nationalities, while a majority are women of the Global South.
} 
trajectories. Some interviewees have spent their entire career in the UN system ${ }^{5}$ while others entered a senior level UN position after careers in domestic politics or in the foreign service of their countries. Interviewees were for the most part in the same age group, meaning that they started their professional careers in the 1970s. They therefore belonged to roughly the same generation of women which may have had an effect on how they perceived of leadership and their roles therein (see Billing 2011, 313).

Consent was obtained to use the interview material according to the Chatham House Rule. ${ }^{6}$ Therefore, for the purpose of the article, I assign first-person pseudonyms to my interviewees (Ane, Karabo, Rin, Sia, and Vaneet), ${ }^{7}$ while not disclosing their institutional affiliations. Interviews included a common set of questions, opening with "Please tell me what inspired you to work for the UN?" This was succeeded by open-ended questions about their leadership experiences asking them to reflect both on their identity as 'women leaders' or 'leaders.'8 I used more specific questions to clarify particular aspects raised by the interviewees. Each interview closed with "What would be your piece of advice for future women leaders in the UN?" As the interviewees sometimes combined career trajectories outside and inside the UN system, some of their remarks refer not only to the UN system.

In handling the transcripts, I did not follow an explicit coding mechanism. Instead, I identified patterns in and across the transcripts that corresponded to practices according to the four analytical processes I stipulated as essential for analyzing the

\footnotetext{
${ }^{5}$ While the focus of this study is the UN Secretariat, interviewees often reflected on their leadership experiences in specialised agencies and programmes across the UN system.

${ }^{6}$ The Chatham House Rule allows using verbatim quotes in published works but without identifying the source. When preparing the manuscript for publication, I got back in touch with my interviewees on this matter. Unfortunately, I could only correspond with one out of five interviewees as the four other interviewees retired in the meantime and do not have publicly available email addresses. In preparing this manuscript, I have taken great care to ensure that interviewee' backgrounds cannot be implicitly or explicitly read from the excerpts included.

${ }^{7}$ I used first-name pseudonyms rather than numbers because the latter encourages more distance to the interviewees as individuals and to their subjectivities. For me, the point and benefit of narrative analysis is to reduce that distance. I purposely chose first names associated with the Global South ethnicities/nationalities to reflect this heritage and retain its presence, while maintaining anonymity. Using first names associated firmly with the Global North would skew this perception.

${ }^{8}$ The questions posed included the following: 'What were your experiences as a women leader in the UN and other professional environments you worked in. Did these change over time?'; 'Who or what inspired you to take on leadership roles? How would you characterize your leadership style? What achievements are you most proud of?'
} 
UN Secretariat as a gendered institution: positional divisions, symbols, everyday interactions, and gendered components of identity. My goal for presenting this model is not replicability. Following an interpretive understanding, any method “(...) will likely yield different results in the hands of different theorists" (Ackerly, Stern, and True 2006,7$)$ as the very nature of the social world is unstable and researchers are not simply interchangeable in how they approach a research project (SchwartzShea and Yanow 2012, 92-95). While I posit that my framework provide useful insights for the purposes of studying barriers to women leadership in gendered institutions such as the UN, my application of this framework is, as I think any application will be, highly contextual.

In analyzing interview transcripts, this article values reflexivity: I constantly reconsider my interpretations and acknowledge that they are not meant to be authoritative. I will therefore include lengthy quotes from my transcripts to leave room for other interpretations (Harel-Shalev and Daphna-Tekoah 2016, 179). The transcripts represent rich texts that are open to various readings. It is likewise important to acknowledge the open-endedness of the texts, echoed by the narrative form: a narrative always implies interpretation, neither the author nor the scholar, in my case, have full control of the narrative (Bode 2015, 47-49). This lack of generalizability is intentional and not read as a problem but as an opportunity: narrative analysis opens up possibilities for studying gender in the UN system through the multitude of experiences of women leaders. In presenting my narrative analysis, I do not look for one 'correct' version of social reality, but for "various experiences or viewpoints (...) in order to understand nuances more fully" (SchwartzShea and Yanow 2012, 105). My five interviewees are therefore only an indication of that multitude.

\section{Practicing gender inequality: The narratives of women leaders}

The following section interprets the interviewees' scripts as narratives, uncovering practices across the four interconnected processes sustaining gender inequality in the UN Secretariat. I will use these processes as structuring devices throughout the section although they often overlap. This is to be expected, as the gendering of institutions is a constitutive process. As such, studying gendered institutions does not 
assume causal patterns in time but instead asks how they are constituted. Practices sustain and inform the four gendered processes identified above - and these practices become accessible through narratives. These relationships are precisely what make it hard to keep the categories distinct as they interact and co-constitute each other.

\section{Gendered positional divisions: Entering 'a men's world'}

All interviewees shared a sense of entering 'a men's world' in their professional careers. It did not matter if they traversed domestic career trajectories, started off in the UN system, or took senior leadership positions in the UN. They offered varied experiences when asked whether this has changed throughout their careers. Interestingly, women who remained in the UN system for the duration of their careers reached more positive conclusions than women who were appointed to senior positions coming from other fields. I will illustrate this point with two narrative quotes. First, consider Rin's comparison of the UN at the beginning of her career and at the time of the interview:

When I first joined, it was completely a men's world, completely. I remember, at some point, I was the minute-taker. Sometimes I would follow the big bosses to the senior management group meetings of the SG (Secretary-General) in the big boardrooms. And I would sit behind and take notes. Even taking notes behind I felt intimidated, because it was all men, in a big boardroom with heavy leather chairs, very intimidating. You had the occasional woman, occasional woman. But today (...) just with your eyes, you go around the table, I would say at any point in time, it's probably close to 50-50. (...) And the dynamics around the table when you have almost half like that, it achieves the concept of minimum critical mass. There's no point of having the focus on one or two because I think either you are intimidated or if you say anything at all, you are seen to be endorsing what everybody else says. But if you are the minimum critical mass, and I would say that's $30-40 \%$, then suddenly, I am not afraid to speak out. I am not afraid to speak out, (...) I don't care who is in the room. 
Rin provides an illuminating comparison between two different time periods in the UN Secretariat. Her account also underlines many further observations of interest when considering gendered positional divides. At the beginning of her career, Rin quite literally took the back seat; her entire purpose of participating in the meetings she recounts was for note taking. Combined with her description of the intimidating atmosphere created by the particular boardroom setting, this illustrates how positional divides and the 'men's space' manifest in practices.

For her, this atmosphere changed with more women on the table. She felt that the sheer presence of more women in positions of authority had a direct effect on what is considered 'appropriate' behavior for women. Rin draws on the notion of minimum critical mass, a prominent concept in scholarship: women leaders are expected to make a difference only when a minimum critical mass, usually one-third, is reached (e.g. Moss Kanter 1975; Dahlerup 1988). As Rin begins to see herself as a 'normal' participant in high-level meetings, her positionality changes and she is able to challenge gendered positional divides. Rin's account therefore mirrors changes in practices constituting gender constructions in line with the expectations of the scholarly literature on minimum critical mass.

Ane, who entered the UN system at a senior level, presents a different perspective:

Oh, I must say that the UN is even more male-dominated as a workspace. And I was privileged to be taken in at a higher position, as a D-2 level. But all other directors in my organization were men. So, it was a very male-dominated environment and gender sensitivity, the status of women, was basically lip service. And I remember, we were being asked to appoint gender focal points. So, every organization has a gender focal point at that time. It wasn't something that was felt as a compelling duty of the senior managers to do something about it. (...) They always found a reason for why there should be no gender balance first of all in recruiting, then retaining and promoting. This was the kind of atmosphere that had been there before; it is changing, but not enough.

Ane's experiences speak of the continued presence of gendered positional differences in the UN Secretariat. In addition, she observes that senior-level staff perceived reaching gender balance as an add-on, almost bordering on a nuisance, 
but certainly a low priority. This echoes how ensuring that women are recruited and maintained in senior leadership positions may be perceived by certain actors in the UN as "tokenistic, empty gestures that are additive as opposed to transformative" (Pruitt 2016, 3).

It also indicates how the UN Secretariat's bureaucratic nature (see Barnett and Finnemore 2004) and functioning may contravene overt normative practices towards fostering gender balance, especially when these conflict with procedural standards, such as efficiency and effectiveness associated with, for example, filling positions quickly (see also section on gendered components of identity). Combined with the idea of tokenism, such thoughts may also be based on the "merit myth," i.e. that gender quotas will allow less 'qualified' women to advance. ${ }^{9}$ However, studies on gender quotas demonstrate the contrary: women elected as Members of Parliament for the British Labour party, for example, are no less and often more experienced than their male counterparts (Nugent and Krook 2016). Interestingly, Besley et al even show that gender quotas "had an immediate effect on the competence of male leaders by triggering a wave of resignations of mediocre leaders" $(2017,2242)$.

Returning to Ane's narrative, her switch from "we" to "they" in recounting her story is insightful: she speaks of "we" when mentioning how her organization was approached to appoint a gender focal point. She then moves to "they," distancing herself from the group of "senior managers" that she was still part of as a Director. This indicates how being the only woman leader in her organization ultimately affected her sense of belonging.

We can see here how the interviewees' responses indicate diverse practical ways of entering 'a men's world'. While Rin's experience speaks of marginalization and intimidation, Vaneet describes this as challenging but also empowering:

My personal experience, and this is very, very, personal is - when I started out, very young, I had to work a lot, a lot, a lot with men (...) I had to adjust my mind a little bit to the way they work. And I did. At the same time, I thought, "I don't want to be the only one, I am going to do something so that women are here."

\footnotetext{
${ }^{9}$ I want to thank an anonymous reviewer for drawing my attention to this point and these studies.
} 
That's why probably I am here. And I think if we do an analysis of what is happening in the UN system, what is happening in the private sector, what is happening in the political sector, what is happening in trade unions, by the wayyou find more or less, obviously we cannot homogenize across the different countries, but there is a pattern, there is a trend. Obviously, we have more advancement in one than in the others, but you can see that the glass ceiling is always there.

Vaneet therefore narrates how working in 'a men's world' and experiencing positional divides inspired her to pursue leadership positions in the first place. She underlined this further at a different stage of her interview: "I didn't come from the feminism movement. It's not that I am not a feminist, but I was not involved in this type of activities, formally. I was an international lawyer, a company lawyer. But I realized that 'No, enough is enough.'" It is interesting to see that Vaneet, as an outsider coming into the UN system, finds its gendered positional divides and the practices sustaining them comparable to that of other sectors. This supports why it makes sense to analyze the UN Secretariat as a gendered institution, notwithstanding its explicit normative commitments.

Finally, another part of Vaneet's narrative provides an instructive comment on hierarchies in topics of organizational importance at the UN Secretariat. This illustrates the continued replication of 'high versus low politics' in the world organization:

When we talk about women, people think that it's a very low area of thematic work. (...) You see (this divide) still in the UN system, you want to talk about gender equality and women's empowerment; people look at you a bit 'meh.' But if you say, I have done a survey on electoral systems and conflicts in different countries, people look at your differently.

In sum, the women's narratives point to practices sustaining gendered positional divisions in the UN Secretariat that confirm expectations of gender inequality and subordination. There is also evidence of a continued hierarchical division of high and low politics, with adverse effects on gender balance. Still, the narratives offer different perspectives on whether the UN Secretariat has changed for the better. 
Looking back at her own UN career, Rin concluded that since having reached minimum critical mass in senior management meetings, their atmosphere has changed substantially. But this may also be an effect of her growing seniority in the system. To fully contextualize this assessment of a senior woman leader, one would need to ask more junior female employees about their perspectives. ${ }^{10}$

\section{Gendered symbols: Women and the 'field' in the United Nations}

The 'field' emerged as an important symbol structuring gendered hierarchies in the UN Secretariat. In UN terminology, 'in the field' is used to describe the organization's operational activities in host countries. It is a powerful image that, for many UN staff, represents the epitome of the organization's work. This is encapsulated in Karabo's narrative when speaking about colleagues reluctant to go into the field:

Very often, people come to me, and they say, you know, "I want to work for the UN," (...) but either they are scared or they're reluctant, or for whatever reason, they say, "I got to be in NY, I got to be in Geneva, or in Vienna or something." So then, I think, that's not the UN. I know that there are very brilliant people who are in legal work and do the normative work (...) and that's fine. But for everyone who is doing anything outside of that, whether you are a human rights officer, a political officer, (or) a civil officer. You are working for the UN (and) it is about this entire global community.

While all interviewees agreed on the status field experience occupies within the UN as a work environment, they come to different conclusions when connecting this to women leaders. Here, it is important to note that the field emerged as a shared symbol across the interviews without prompting from my side. This indicates that the interviewees pointed to an implicit challenge when reflecting on women, field experience, and promotion in the UN system. Two basic evaluations come out of their narratives: they either consider field experience a challenge for women leaders, often combined with evoking particular constructions of 'feminine' objectives in

\footnotetext{
10 I want to thank an anonymous reviewer for drawing my attention to this point.
} 
balancing career and family life, ${ }^{11}$ or they do not to consider this as a challenge specific to women.

Compare Rin's narrative:

I spent ten years in Africa, six years in Zambia, four years in Kenya at a time when a lot of young women (...) find it very difficult to go to the field, especially if they are married with children, because husbands have their careers as well. So, that's still a problem with us today. And often they get shortchanged, because they are not able to move the way men do and thus build up credibility among themselves and promotion becomes a normal expectation. Because the nature of our work is, your credibility comes very much from knowing what is going on in the field. And women, unfortunately, they are shortchanged (...), because of tradition, they are not able to go. And then it's constantly a struggle to stay in New York because people look at you in a different way: "You are not credible." Or "why did you pick this field?" (...) I feel very, very... My heart really goes out for these women that are smart, they can't go, yet they like the UN, they want to remain here. And then their credibility is always tested, always tested. Whether it comes to deploying them, to putting them on a particular post, on a career track, on a promotion track.

Here, going to the field clearly comes out as the symbolic marker of promotion and credibility within the UN system. Likewise, Rin portrays field experience as something many women are struggling with because of gendered hierarchies. She makes this explicit when mentioning 'husbands' careers' and also when drawing attention to 'tradition' as a factor that may constrain women in gaining field experience. It becomes clear how "unequal career progression (is) based on the deep-seated gendered bias" (Shinozaki 2014, 528) towards the career of the husband.

As Rin has gathered significant field experience, she exempts herself from the group of women for whom going to the field is difficult. Yet, in drawing attention to field experience as a persistent 'problem' for many young women, Rin also contributes to

\footnotetext{
11 I will revisit work-life balance in the subsequent section on everyday interactions enacting gendered divisions.
} 
affirming a particular construction of women as not wanting to or/and not able to go to the field as much as men. Interestingly, neither her career trajectory nor those of the other interviewees capture this. All five senior female leaders I talked to had field experience and combined their work with family life. This reflects the complex functioning of gendered symbols and the hierarchies they sustain: women leaders are confronted with them, find strategies to deal with them, but still identify field experience as 'problematic' for women. It also demonstrates how reflectiveness and reflexivity can interact in women leaders' practices: Rin not only expressly reflects on her own career trajectory integrating field experience but also shows the working of background knowledge acquired within the UN's gendered organizational context when talking about other women.

Ane's account is somewhat complementary to this narrative. But her explicit use of "we" in the following quote clearly implies that she considers herself as part of a group of women with field experience who have disproved gender roles:

There are many instances where you associate women with certain kind of jobs, that kind of men's space, certain positions should be for men. I think we broke that, we broke that and over the years, women officers have done very well, disproved these gender roles. We can't do hard postings - we have done hard postings. We can't do high-pressure work - we have done them.

Ane also identifies necessary policy responses to diversify women's choices:

How do they accommodate their family concerns? This is particularly important in the field. There are some very courageous women who are going to Niger, who are going to Cote d'Ivoire. (...) Now we have one of our colleagues, who was very happily ensconced here, but she chose to go on a very difficult mission to Niger. So, there are young women who are going out there, but as you grow older, as you have responsibilities for a family and women have the care-burden, they feel themselves more responsible. How do you accommodate all of that? I think it's not enough to look at the policies of recruitment and promotion but also at the policies relating to (...) retention. (...) At the present rate, we are years and decades away from parity. 
By pointing out examples of women intent on going to the field, Ane underlines that this part of the UN system's work environment does not have to be a 'necessary' challenge for (especially young) women. Yet, she also qualifies her description in characterizing family responsibilities and the care-burden as part of women's lived experiences at a later stage of their lives.

Ane's observations on field experience point to interesting dynamics regarding spatial mobility, gender, and the family. Unfortunately, these connections have only received little scholarly attention: research on spatial mobility of highly-skilled professionals often concentrates on single (male or female) professionals or only covers particular employment sectors (Shinozaki 2014, 528). In the context of academia, for example, Ackers' study demonstrates that the spatial mobility of female scientists drops due to childbearing and child-rearing (2005). Yet, the UN represents a significantly different work environment that has to be accounted for. Nowicka's study on the concept of 'home' among transnational UN professionals provides a characteristic description of this context. Talking about her interviewees, she summarizes:

Due to the character of their work, they travelled or lived in the so-called developing or transition countries. As a result of specific employment conditions in the international organization, many swap assignments every three to five years, and this, in turn, often means a change in place of residence. (...) 'Grabbing the chance' is part of this general life plan. (...) The interviewees assume that discontinuity, such as a change of job or residence, is an integral part of a person's biography. The institutional structure of the international organization enforces this way of designing one's life.

This provides an excellent representation of the UN as a work environment - and the particular challenges attached to an environment that considers such high mobility as 'normal' and necessary in order to advance. Interestingly, this environment and its associated workloads privileges either the single, unattached male/female or means that all employees "need a wife" or a supportive partner as a "professional asset," allowing them to pursue demanding full time jobs while still enjoying family 
life (Crabb 2015, 4). ${ }^{12}$ It therefore presents challenges to subordinated femininities and masculinities and circulates a heroic narrative centered around courageous and autonomous and independent masculinity (see Tickner 1992, 6).

Vaneet's narrative identifies another layer of practices in this mix, while echoing some of the previous statements and assessments:

We have to realize that the UN is very particular. We are talking about living in many different countries where in many countries you cannot take your family. No family duty station. (...) If you go to Afghanistan, if you go to Iraq, I think it's hard. And I see this (...) in many other paths of life where women are probably not so much willing to shift to a professional role with a very important difficulty on the family role. Is it because they don't want to? Yes, it is because they don't want to. Is it because the culture and the structure of the society make it more difficult for them? Yes indeed. Both things. I could not say it's only the culture and the structure. We like to have a balanced life, we try to do both as much as we can. I think it's something also, part of our core way of being. (...) To get up within the UN system, you would need to be able to go to places that are not so good for women. (...) If you are going to do the career inside the UN system, you need to have field experience, definitely, independent of what is your area of work. You cannot avoid places where it is difficult to bring your family.

Vaneet connects potential challenges related to field experience directly to an 'essentialist' conception of femininity: in mentioning 'our core way of being' as well as 'vulnerabilities' of women ("places that are not so good for women"), her narrative shows tendencies of representing "'women' as an undifferentiated category across time, class, race, and culture" (Tickner 2001, 15). Vaneet's narrative therefore speaks of masculinized practices within 'the field' where women do not really have a place, not only because work-family balance is assumed to be more important in the lived experience of women but also because it is not 'safe' or 'appropriate'. This echoes literature on women and security: as conflict zones are constructed as gendered, "masculine spaces" that are unsuitable for women,

\footnotetext{
12 I want to thank an anonymous reviewer for drawing my attention to this point.
} 
women peacekeepers, for example, tend to be deployed to "least risky missions" (Karim and Beardsley 2013, 469-70; see also Goldstein 2006). ${ }^{13}$

Finally, Karabo's narrative provides a different perspective as she does not consider fieldwork a challenge for women in the UN system:

What was it like to have the career? I always felt that it was smooth. For me, I don't know, maybe it is part of an attitude. I counsel a lot of young people because I feel: "You can all do it." And, I was married (...), I had two children. So, you know, I always tell people: "It is possible. It's possible to be married, it's possible to have a family. It's possible to do the field work, my children loved it." So, it's possible. And, of course, there are sometimes individual problems or constraints that people have.

Karabo is the only interviewee to make an explicit connection between her own experiences as senior woman leader in the UN system and those of other female staff. Still, and while more implicitly, the assumption that women are more concerned with the work-family balance than men continues here. The continuous presence of the work-family balance as an implicit or explicit issue in all interviewee narratives speaks of its symbolic status within practices sustaining gender divisions in the UN system. This should not be very surprising as the UN Secretariat is a social work environment like any other and therefore subject to similar pervasive notions of gender as a social practice. ${ }^{14}$

In sum, the narratives have identified the field as a clearly gendered symbol around which practices manifest themselves in the UN Secretariat. The field rests on gendered hierarchies and divisions as it privileges a certain type of masculinity for advancement and promotion in the UN system and likewise draws attention to an array of additional gendered subordinations in relation to spatial mobility and family life. The interviewees display varied ways of engaging reflectively and reflexively with the field in their narratives: by distancing themselves and their career

\footnotetext{
13 I want to thank an anonymous reviewer for drawing my attention to this point.

14 On a connected side note, there is an interesting formal practice of listing the names of spouses on the list of senior UN officials of USG/ASG and equivalent rank published by the UN's Protocol and Liaison Service (United Nations 2016).
} 
trajectories from the experiences of other women in the UN system or by bringing those experiences into line with their own.

Enacting gender divisions in the everyday: The importance of networking and the elusive work-life balance

As most of the interviewees reflected on their career trajectories in the course of the interview, getting to everyday interactions and the practices therein was difficult. However, some of these reflections contained elements of everyday practice indicative of the 'typical' situations they encountered throughout their careers. As the title of this section implies, two themes appeared often across interviews: worklife balance and networking. Again, the interviewees presented diverging perspectives, largely dependent on whether they perceived the greater value they placed on their work-life/family balance as a gendered component of their individual identities or not.

Sia connects the value placed on work-life/family balance to overall social expectations tied to women pursuing careers:

A common challenge I had faced in all positions of leadership was how to balance career and family. (...) No matter how important your work is, it is still your responsibility to make sure that your children have food on the table, get them into the right and best school, make sure they do their homework, follow their progress in school. Your family will always require your attention. (...) Your children see you as mum and your husband sees you as his wife. Period. That means taking their phone calls even in the middle of important meetings, wherever you are in the world. Always having to work the double shift and trying to balance the scale in a way that neither suffers can be very difficult. I cannot tell how many times my husband has called me at some ungodly hour to tell me he did not like the food that had been given to him (...). Or my son calling me crying on the phone to tell me that his school sport t-shirt was not the right color or his father had refused to attend his school drama performance. This can be extremely trying for a woman. The reality is that as women there are specific tasks, which we inherited from our mothers that we are expected do as women 
despite being working mothers. I think we are yet to arrive at a place and time where we can share responsibility for the family.

Based on Sia's narrative, it is easy to imagine how different expectations people in her life place on her have influenced her career. Her mention of "taking their phone calls in the middle of important meetings" acknowledges that this departs from 'established' practices in a professional setting and may have lead to negative reactions in the past. Her portrayal of "specific tasks, which we inherited from our mothers" is clearly shaped by gendered components of her individual identity as a mother and a wife.

Sia describes what has been called the "second shift" (Hochschild 2012), the gendered nature of primary care responsibilities and their adverse effects on workplace equality. Hochschild's finding that the "unpaid work of childcare and housework is mostly performed by women" continues to find support in recent studies as “(...) women still face fewer opportunities for work involvement, pay, and public life" (Blair-Loy et al. 2015, 436, 439).

Other narratives also highlight how this double burden enacts gendered divisions in the everyday. Ane notes:

There was a time when one of my bosses said to me: "You go away at lunch time and take your daughter for swimming. And then you are always concerned (with these responsibilities)." So I told him: "Look, as long as I am doing my work, you have no problems with my work." And he would swear by me otherwise. "This is something I have to do, this is part of my work-life balance. I have a certain duty towards my daughter." (...) Sometimes I found that they were not so used to having as many women around who had family responsibilities. (...) I used to be very self-conscious about people, not saying that I was taking time off from work, unauthorized time, for anything personal.

Ane's articulates her "self-consciousness" around how her role as a mother may be seen to interfere with her work. Again, this points to the presence of strong, established practices of work taking priority over everything else - and how this may be encountered as a challenge for women leaders at the UN Secretariat. These descriptions are obviously full of particular constructions of femininity and 
masculinity. In Ane's observations, work-family balance is only perceived as a 'problem' for women, i.e. the story implies that this was not an issue before women occupied senior positions meaning that men are not seen to have these family responsibilities. This supports my previous argument about how a particular version of masculinity has come to constitute the "normal" employee in the UN Secretariat.

Moving on to a second theme, networking is portrayed as another set of everyday practices structured around gender divisions in the UN Secretariat. This is apparent in Vaneet's narrative:

Networks are critical. (...) But women have not been part in many cases of networks of top leadership positions. (...) There is an informal setting that nobody will tell you that it's there. And you need to cope with that and you need to be able to manage that. (...) They are not created to go against women, not at all. It's just the networks that are there and the members that were there were mainly men. And they articulate surrounding around what their preferences are. And sometimes these are not our preferences. (...) And this is something nobody is going to tell you and you have to discover yourself, what is not in the book.

The presence of everyday networking practices as summarized by Vaneet speaks of assumed gendered divisions structuring them, for example assumed diverging preferences between men and women that sustain networks. She also brings networks' male-dominated character back to positional differences. In other words, because there are fewer women in leadership positions, networks remain mostly male. This is an apt illustration for how the different institutional processes sustaining particular constructions of gender in the UN system may inter-connect. Also, these impressions are not specific to the UN as an organizational environment: there is considerable literature in the social sciences outlining how "male support systems" (Bagilhole and Goode 2001, 162) of the type Vaneet describes "(can) provide challenges for women's incorporation into organizations, their career advancement, and their opportunities to influence" (Barnes and Beaulieu 2017, 462; see also O’Brien 2015). 
Vaneet addresses networking practices as something women have to 'manage' or 'cope with,' implying that if women want to become leaders, they just have to adapt. This is another point where diverging approaches between interviewed women leaders come out. Talking about networking, Ane remarked:

For example, I don't drink. I don't drink alcohol and yes, sometimes, it's a disadvantage that I can't sit down with guys and drink them under the table, kind of bond at the bar. But, these are things that you do in different ways, you relate on different plains. You don't necessarily have to follow the traditional ways of networking and diplomacy.

Ane does not think it is necessary for women to 'conform' to existing everyday interactions along gender lines in the form of networking practices in order to advance in the UN system. Instead, she considers other possibilities, challenging established, 'traditional' ways of doing things - especially in the UN as a multicultural environment. We see how particular types of networking may not only challenge the gendered part of Ane's identity but also others that are related to culture, religion or even health. I will return to these other, intersectional aspects in the next section.

In sum, everyday interactions surrounding networking and work-life/family balance sustain gendered divisions in the UN system. The narratives demonstrate different ways of navigating these constraints and underline encounters with a particular construction of hegemonic masculinity as the 'normal' employee, especially in terms of the 'double burden.'

\section{Gendered components of plural identities}

As the last section demonstrated, gendered components of individual identity clearly come into the practices of everyday interactions enacting gender divisions. This demonstrates that these processes are interconnected. Again, the narratives contain considerable diversity in how interviewees understand and portray their identities. While some interviewees reflected on non-gender parts of their identity, bringing me to the issue of intersectionality, many framed other parts of their identities in gendered terms. Yet, cultural differences played some role in their narratives, as 
Ane's example in the last section demonstrated. Consider Karabo's account in this context:

In Afghanistan, I travelled for miles, sat down with tribal chiefs and drank tea with them. And you know, very often, people ask: "Was it difficult as a woman?" And, you know what, never. Never, never, never. And again, I think it's how you project yourself. For example, case in point, in Afghanistan, I never covered my hair. But I saw a lot of Western women who felt that they had to cover their hair. But, now of course it may be different with the influence of the Taliban in so many areas. (...) I never ever had a problem that they didn't receive me or that they felt that it was disrespectful. So sometimes, we make assumptions. But I think it's being comfortable with yourself.

Karabo explicitly refers to how assumptions made about gendered components of women's identity, especially accepted among 'Western women,' are detrimental to how women fill out their roles in 'the field.' Her narrative can be read as an attempt to counter these assumptions and their tied-in practices, thereby enacting a set of diverging practices.

Sia notes how cultural, social and gendered parts of her identity interacted in shaping her incentive to considering leadership roles:

My mother was probably my greatest inspiration. I grew up in a (...) Muslim home and experienced discrimination on the basis of my gender from early childhood all through adulthood. As a young girl going up in this environment I became keenly aware of how differently girls and boys were treated. Whereas I was made to feel like a second-class citizen and a burden to my family, boys were treasured and desired, and expected to behave like the head of the family.

Other accounts refer to conflicts between different parts of identity. For Rin, gendered components of her identity as a woman in support of affirmative action interfered with other components of her identity as a senior manager. In talking about former Secretary-General Ban's commitment to increasing the number of women in senior leadership positions she notes: 
And I really have to give credit to this SG (Secretary-General) for consciously making it happen. You know we send up candidates for people we interview, for high-level positions here, for D-2 and above, and if I don't have a woman amongst the group, he rejects the whole file. So, if I don't find anybody, fine, readvertise and go back again. And that's the way to do it, there is no half-way to do it. (...) I get very mad, because I want the person on board quickly, but that's the way it is here now. And it's the same in a lot of funds and programmes, but the Secretariat is a sea change.

This excerpt draws attention to the plural nature of individual identity and how it may manifest itself in reflectively performing diverging practices depending on the situation.

Adding another angle to this discussion, some interviewees' transcript, such as Vaneet's, are full of references to "we" and "us", reflecting a shared sense of women as a group. During the interview, she used this often to create a sense of 'we are in the same boat, this is something we share,' and I felt that my positionality as a female researcher influenced the atmosphere and content of the interviews I conducted. ${ }^{15}$ Conducting interviews is, of course, always concerned with establishing a conversational context with another human being. But given the particular substantive topic of women leadership, all interviewees in more or less direct ways appealed to the gendered component of my identity.

In sum, how narratives speak of gendered components of their identity provides us with access to another layer of practices sustaining gender divisions in the UN Secretariat in a very personal form. Narratives show the complex processes of interaction and sometimes conflict between the varied components of women leaders' individual identities, integrating culture, organizational roles, family socialization and the like, while gender consistently comes out as an important marker. Once again, we also see the presence of reflectiveness and reflexivity in women's practices: they are embedded within the gendered organizational culture of the UN as background knowledge and also deliberately reflect on changing it.

\footnotetext{
15 Vaneet would often make this connection very explicitly in asking, for example: "But it's the same at universities, no?"
} 


\section{Conclusion}

Starting from the empirical puzzle that senior leadership positions in the UN system continue to be dominated by men despite the UN's overt commitment to reaching gender parity, I suggested using feminist institutionalism to analyze how gender constructions sustain continued gender imbalance in practices. This allows us to analytically approach the UN Secretariat as a gendered institution and to examine practices constituting gendered divisions through qualitative methods at the microlevel, therefore making a contribution to the often-quantitative literature on constraints to women leadership.

Based on early feminist institutionalist scholars, I argued that we can visualize how gendering within the UN as an institution works through studying practices in four inter-connected processes: gendered positional divisions, symbols, everyday interactions, and gendered components of individual identity. Narrative analysis of semi-structured interviews with senior women leaders offers the methodological entry point to these practices. The study followed an interpretive design and considered the narrative form as particularly suitable for this endeavor because it acknowledges the multitude of perspectives sustaining gender constructions and emphasizes that these are inherently open to interpretation. Further, I contextualised the practices and the topics that emerged in my narrative analysis with relevant academic literature. The analysis of five narratives provided us with varied insights to the puzzle of lacking leadership of women in the UN and how practices work to sustain gender inequality, thereby hindering gender parity spanning all levels.

First, senior women leaders spoke of gendered positional divides, both in terms of perceived gendered constructions of leadership behavior and a lack of attributed importance to increasing gender parity in the UN Secretariat. At the organization's higher echelons, the UN therefore still appears as a men's world. This may change over time as data collected by UN Women shows: gender parity has been reached at the lower pay scales P-1 and P2, and numbers from P3 to P-5 level show clear improvements (UN General Assembly 2017c). But other barriers may still hamper advancement: top leadership positions in the UN system are frequently political 
appointees, meaning that the UN Secretary-General has little immediate control over career progression to key Under-Secretary-General posts, e.g. the UnderSecretary-General for Political Affairs.

Second, women's field experience emerged as an important marker of promotion that is clearly gendered in the sense that narratives identified it as a challenge for aspiring women leaders to go to the field. A particular version of hegemonic masculinity can be seen to emerge here, casting the ideal UN professional as strong, independent, courageous and highly mobile. Analyzing this "heroic field ideal" in further detail comes out as a particularly interesting path for further research, especially in combination with mapping the experiences of women and their coping strategies in the field, providing information that is currently lacking. The UN provides some data on leadership positions in the field and the share of women among the civilian staff of UN peacekeeping operations: at $22 \%$ and $28 \%$, the numbers remain far from gender parity (UN General Assembly 2017b, 2017a).

Third, in the everyday, practices sustaining gendered divisions manifested most clearly in relation to networking and the work-life/family balance. Here, the "second shift," the gendered nature of primary care responsibilities, appeared in the narratives as a hamper to gender balance at the workplace.

Finally, when reflecting on their identity, many interviewees highlighted gendered aspects, detailing, how plural parts of their identity, that is their culture or their organizational role, interact with each other - sometimes with adverse effects. Therefore, analyzing women leaders' narratives not only brought out gendered practices in the UN system enacted by others, but also saw themselves act in reflexive and reflective manners as performing agents in both sustaining and challenging these practices.

Overall, my article demonstrates the viability of using narrative analysis in order to get to practices. While I only worked with a small number of narratives, their detailed analysis and reading provided interesting insights into practices sustaining gender inequality and therefore hindering gender parity in the UN, but also many avenues for further research. Similar fruitful narrative- and practice-based research can be envisioned across different international organizations, including within the UN system, in order to assess differences and similarities between them. 
The inherent quality of narratives as highly individualized portrayals of social situations does not allow me to draw general conclusions. Indeed, closely engaging with the narratives of senior women leaders also served to highlight a dearth of systematic data on social aspects of the UN Secretariat's internal employment structure, such as the respective importance of work-life balance among UN employees, the importance of networking, and the relevance of mentoring programs. In order to provide a comprehensive overview of the workings of gender inequality at the UN, more comparative data would need to be collected.

At the same time, and while this collection of data would be important, constitutive models providing a detailed, micro perspective on the practices sustaining and challenging gender inequality can provide a deep visualization of women leaders' lived reality in international organizations. In doing this, my analysis re-introduced substance and individuality into our knowledge about women leaders in the UN bureaucracy.

\section{References}

Acker, Joan. 1990. "Hierarchies, Jobs, Bodies: A Theory of Gendered Organizations." Gender and Society 4 (2): 139-58.

- - . 1992. "From Sex Roles to Gendered Institutions." Contemporary Sociology 21 (5): 565-69.

Ackerly, Brooke A., Maria Stern, and Jacqui True. 2006. "Feminist Methodologies in International Relations." In Feminist Methodologies for International Relations, edited by Brooke A. Ackerly, Maria Stern, and Jacqui True, 1st ed., 1-16. Cambridge, UK: Cambridge University Press.

Ackers, Louise. 2005. "Moving People and Knowledge. Scientific Mobility in the European Union." International Migration 43 (5): 99-131.

Ansorg, Nadine, and Toni Haastrup. 2018. "Gender and the EU's Support for Security Sector Reform in Fragile Contexts." JCMS: Journal of Common Market Studies 56 (5): 1127-43.

Bagilhole, Barbara, and Jackie Goode. 2001. "The Contradiction of the Myth of Individual Merit, and the Reality of a Patriarchal Support System in Academic Careers. A Feminist Investigation." The European Journal of Women's Studies 8 (2): 161-80.

Barnes, Tiffany D., and Emily Beaulieu. 2017. "Engaging Women: Addressing the Gender Gap in Women's Networking and Productivity." PS: Political Science \& Politics 50 (2): 461-66.

Barnett, Michael N., and Martha Finnemore. 2004. Rules for the World: International Organizations in Global Politics. Ithaca, NY: Cornell University Press. 
Besley, Timothy, Olle Folke, Torsten Persson, and Johanna Rickne. 2017. "Gender Quotas and the Crisis of the Mediocre Man: Theory and Evidence from Sweden." American Economic Review 107 (8): 2204-42.

Billing, Yvonne Due. 2011. "Are Women in Management Victims of the Phantom of the Male Norm?" Gender, Work \& Organization 18 (3): 298-317.

Blair-Loy, Mary, Arlie Hochschild, Allison J. Pugh, Joan C. Williams, and Heidi Hartmann. 2015. "Stability and Transformation in Gender, Work, and Family: Insights from the Second Shift for the next Quarter Century." Community, Work \& Family 18 (4): 435-54.

Bode, Ingvild. 2015. Individual Agency and Policy Change at the United Nations: The People of the United Nations. London: Routledge.

- - . 2017. "Where Are the Female Leaders at the UN? Gender Bias Persists." Pass Blue: Independent Coverage of the UN, published August 28, 2017, accessed 10 November 2018, https://www.passblue.com/2017/08/28/where-are-thefemale-leaders-at-the-un-gender-bias-persists/.

- - . 2018a. "Expertise as Social Practice: The Special Procedures at the UN Human Rights Council and the Individual Construction of Experts." In Transnational Expertise. Internal Cohesion and External Recognition of Expert Groups, edited by Christian Henrich-Franke, Christian Lahusen, Robert Kaiser, and Andrea Schneiker, 101-26. Baden-Baden: Nomos.

- - . 2018b. "Reflective Practices at the Security Council: Children and Armed Conflict and the Three United Nations." European Journal of International Relations 24 (2): 293-318.

Bode, Ingvild, and John Karlsrud. 2018. "Implementation in Practice: The Use of Force to Protect Civilians in United Nations Peacekeeping." European Journal of International Relations online first. https://doi.org/10.1177/1354066118796540.

Bueger, Christian. 2014. "Pathways to Practice: Praxiography and International Politics." European Political Science Review 6 (03): 383-406.

Bueger, Christian, and Frank Gadinger. 2015. "The Play of International Practice." International Studies Quarterly 59 (3): 449-60.

Burns, Courtney, and Kyle T Kattleman. 2017. "Women Chief Executives: The Political Catch-22 of Counterterrorism." Journal of Terrorism Research 8 (2): 22-43.

Chappell, Louise, and Georgina Waylen. 2013. "Gender and the Hidden Life of Institutions." Public Administration 91 (3): 599-615.

Charlesworth, Hilary. 1994. "Transforming the United Men's Club: Feminist Futures for the United Nations." Transnational Law \& Contemporary Problems 4 (2): 421-54.

Cohn, Carol. 1987. "Sex and Death in the Rational World of Defense Intellectuals." Signs: Journal of Women in Culture and Society 12 (4): 687-718.

Connell, R.W. 1995. Masculinities. Cambridge: Polity.

Cook, Alison, and Christy Glass. 2014. "Women and Top Leadership Positions: Towards an Institutional Analysis." Gender, Work and Organization 21 (1): 91-103.

Cotter-Lockard, Dorianne. 2017. Authentic Leadership and Followership: International Perspectives. New York, NY: Nature America Ltd. 
Crabb, Annabel. 2015. The Wife Drought: Why Women Need Wives and Men Need Lives. Sydney: Read How You Want.

Dahlerup, Drude. 1988. "From a Small to a Large Minority: Women in Scandinavian Politics." Scandinavian Political Studies 11 (4): 275-98.

Deiana, Maria-Adriana, and Kenneth McDonagh. 2018. "Translating the Women, Peace and Security Agenda into EU Common Security and Defence Policy: Reflections from EU Peacebuilding." Global Society 32 (4): 415-35.

Den Boer, Andrea, and Ingvild Bode. 2018. "Gendering Security: Connecting Theory and Practice." Global Society 32 (4): 365-73.

Elshtain, Jean Bethke. 1995. Women and War: With a New Epilogue. Chicago, IL: University of Chicago Press.

Enloe, Cynthia. 2010. "Foreword." In Gender Matters in Global Politics: A Feminist Introduction to International Relations, edited by Laura J. Shepherd, xvii-xviii. New York: Routledge.

-- - 2014. Bananas, Beaches and Bases: Making Feminist Sense of International Politics. 2nd edition. Berkeley, CA: University of California Press.

Fritz, Claudia, and Daan van Knippenberg. 2018. "Gender and Leadership Aspiration: The Impact of Work-Life Initiatives." Human Resource Management 57 (4): 855-68.

Gibbings, Sheri Lynn. 2011. "No Angry Women at the United Nations: Political Dreams and the Cultural Politics of United Nations Security Council Resolution 1325." International Feminist Journal of Politics 13 (4): 522-38.

Gizelis, Theodora-Ismene, and Louise Olsson. 2015. Gender, Peace and Security: Implementing UN Security Resolution 1325. Abingdon: Routledge.

Global Peace Operations Review. 2017. "2015-2017 Comparative Data on UN Senior Appointments, by Gender." Global Peace Operations Review, published January 13, 2017, accessed May, 9, 2018, http://peaceoperationsreview.org/featured-data\#gender.

Goetz, Anne Marie. 2016a. "Still No Country for Women? Double Standards in Choosing the next UN Secretary-General." 50.50 Inclusive Democracy, published July 28, 2016, accessed August, 12, 2016, https://www.opendemocracy.net/5050/anne-marie-goetz/still-no-countryfor-women-double-standards-choosing-next-UN-Secretary-General.

- - . 2016b. "Still No Woman at the Helm of the UN." 50.50 Inclusive Democracy, published October 6, 2016, accessed December, 10, 2017, https://www.opendemocracy.net/5050/anne-marie-goetz/still-no-womanat-helm-UN.

Goldstein, Joshua S. 2006. War and Gender: How Gender Shapes the War System and Vice Versa. 2. edition. Cambridge: Cambridge University Press.

Gould, Jill A., Carol T. Kulik, and Shruti R. Sardeshmukh. 2018. "Trickle-down Effect: The Impact of Female Board Members on Executive Gender Diversity." Human Resource Management 57 (4): 931-45.

Haack, Kirsten. 2014a. "Breaking Barriers? Women's Representation and Leadership at the United Nations." Global Governance 20 (1): 37-54.

- - . 2014b. "Gaining Access to the 'World's Largest Men's Club': Women Leading UN Agencies." Global Society 28 (2): 217-40. 
---. 2017. "Women, Organizational Crisis, and Access to Leadership in International Organizations." Journal of Women, Politics \& Policy 38 (2): 17598.

Haastrup, Toni. 2018. "Creating Cinderella? The Unintended Consequences of the Women Peace and Security Agenda for the EU's Mediation Architecture." International Negotiation 23 (2): 218-37.

Haastrup, Toni, and Meryl Kenny. 2016. "Gendering Institutionalism: A Feminist Institutionalist Approach to EU Integration Theory." In Gendering European Integration Theory: Engaging New Dialogues, edited by Gabriele Abels and Heather MacRae, 197-216. Opladen: Barbara Budrich Publishers.

Harel-Shalev, Ayelet, and Shir Daphna-Tekoah. 2016. "Bringing Women's Voices Back In: Conducting Narrative Analysis in IR." International Studies Review 18 (2): 171-94.

Hawkesworth, Mary. 2003. "Congressional Enactments of Race-Gender: Toward a Theory of Raced-Gendered Institutions." American Political Science Review 97 (4): 529-50.

Heathcote, Gina. 2018. "Security Council Resolution 2242 on Women, Peace and Security: Progressive Gains or Dangerous Development?" Global Society 32 (4): 374-94.

Hochschild, Arlie Russell. 2012. The Second Shift: Working Families and the Revolution at Home. New York, N.Y: Penguin Books.

Holm, Mette, and Mogens Lykketoft. 2017. "Nudging the Decision on UN SecretaryGeneral from the Security Council." The Huffington Post, published January 10, 2017, accessed 10 August 2017, http://www.huffingtonpost.com/metteholm/nudging-the-decision-on-u_b_14076596.html.

Huelss, Hendrik. 2017. “Be Free? The European Union's Post-Arab Spring Women's Empowerment as Neoliberal Governmentality." Journal of International Relations and Development online first, https://doi.org/10.1057/s41268-0170094-0.

Hurley, Matthew. 2018. "Watermelons and Weddings: Making Women, Peace and Security 'Relevant' at NATO Through (Re)Telling Stories of Success." Global Society 32 (4): 436-56.

Jain, Devaki. 2005. Women, Development, and the UN. A Sixty-Year Quest for Equality and Justice. United Nations Intellectual History Project Series. Bloomington, IN: Indiana University Press.

- - - 2017. "Women of the South: Engaging with the UN as a Diplomatic Manoeuvre." In Gender and Diplomacy, edited by Jennifer A. Cassidy, 15-31. Abingdon: Routledge.

Karim, Sabrina, and Kyle Beardsley. 2013. "Female Peacekeepers and Gender Balancing: Token Gestures or Informed Policymaking?" International Interactions 39 (4): 461-88.

Kaufman, Joyce P. 2013. Women at War, Women Building Peace: Challenging Gender Norms. Edited by Kristen P. Williams. Boulder, CO: Kumarian Press.

Kawakami, Christine, Judith B. White, and Ellen J. Langer. 2000. "Mindful and Masculine: Freeing Women Leaders From the Constraints of Gender Roles." Journal of Social Issues 56 (1): 49-63. 
Kenny, Meryl. 2007. "Gender, Institutions and Power: A Critical Review." Politics 27 (2): 91-100.

Koch, Martin T., and Sarah A. Fulton. 2011. "In Defense of Women: Gender, Office Holding, and National Security Policy in Established Democracies." The Journal of Politics 73 (1): 1-16.

Lahire, Bernard. 2011. The Plural Actor. Translated by David Fernbach. Cambridge: Polity Press.

Landgren, Karin. 2015. "The Lost Agenda: Gender Parity in Senior UN Appointments." Global Peace Operations Review, published December 14, 2015, accessed January 20, 2016, http://peaceoperationsreview.org/commentary/the-lost-agenda-genderparity-in-senior-un-appointments/.

Leander, Anna. 2008. "Thinking Tools." In Qualitative Methods in International Relations: A Pluralist Guide, edited by Audie Klotz and Deepa Prakesh, 11-27. Basingstoke: Palgrave Macmillan.

Lovenduski, Joni. 2015. "Foreword." In Gender, Politics and Institutions: Towards a Feminist Institutionalism, edited by Mona Lena Krook and Fiona Mackay, viixi. Basingstoke; New York: Palgrave Macmillan.

Mackay, Fiona, Meryl Kenny, and Louise Chappell. 2010a. "New Institutionalism Through a Gender Lens: Towards a Feminist Institutionalism?" International Political Science Review 31 (5): 573-88.

McCarthy, Helen, and James Southern. 2017. "Women, Gender, and Diplomacy: A Historical Survey." In Gender and Diplomacy, edited by Jennifer A. Cassidy, 15-31. Abingdon: Routledge.

Moss Kanter, Rosabeth. 1975. "Women and Structure of Organizations: Exploration in Theory and Behaviour." In Another Voice: Feminist Perspective on Social Life and Social Sciences, edited by Rosabeth Moss Kanter and Marcia Millman. New York: Doubleday.

Muehlenhoff, Hanna L. 2017. "Victims, Soldiers, Peacemakers and Caretakers: The Neoliberal Constitution of Women in the EU's Security Policy." International Feminist Journal of Politics 19 (2): 153-67.

Ní Aoláin, Fionnuala, Dina Francesca Haynes, and Naomi R. Cahn. 2011. On the Frontlines: Gender, War, and the Post-Conflict Process. Oxford: Oxford Uniersity Press.

North, Douglass C. 1990. Institutions, Institutional Change and Economic Performance. Cambridge: Cambridge University Press.

Nugent, Mary, and Mona Lena Krook. 2016. "Gender Quotas Do Not Pose a Threat to 'Merit' at Any Stage of the Political Process." British Politics and Policy at LSE, published February 23, 2016, accessed 10 November 2018, http://blogs.Ise.ac.uk/politicsandpolicy/gender-quotas-do-not-pose-a-threatto-merit-at-any-stage-of-the-political-process/.

O'Brien, Diana Z. 2015. "Rising to the Top: Gender, Political Performance, and Party Leadership in Parliamentary Democracies." American Journal of Political Science 59 (4): 1022-39.

Paxton, Pamela Marie, and Melanie M. Hughes. 2017. Women, Politics, and Power: A Global Perspective. Third edition. Los Angeles: SAGE, CQ Press. 
Pietila, Hilkka. 1996. Making Women Matter: The Role of the United Nations. 3rd ed. London: Zed Books.

Pouliot, Vincent. 2008. "The Logic of Practicality: A Theory of Practice of Security Communities." International Organization 62 (2): 257-88.

- - . 2016. International Pecking Orders: The Politics and Practice of Multilateral Diplomacy. New York: Cambridge University Press.

Pruitt, Lesley J. 2016. The Women in Blue Helmets: Gender, Policing, and the UN's First All-Female Peacekeeping Unit. Oakland, CA: University of California Press.

Ralph, Jason, and Jess Gifkins. 2017. "The Purpose of United Nations Security Council Practice: Contesting Competence Claims in the Normative Context Created by the Responsibility to Protect." European Journal of International Relations 23 (3): 630-53.

Reinharz, Shulamit. 1992. Feminist Methods in Social Research. New York: Oxford University Press.

Ridgeway, Cecilia L. 2001. "Gender, Status, and Leadership." Journal of Social Issues 57 (4): 637-55.

Ryan, Michelle K., S. Alexander Haslam, Thekla Morgenroth, Floor Rink, Janka Stoker, and Kim Peters. 2016. "Getting on Top of the Glass Cliff: Reviewing a Decade of Evidence, Explanations, and Impact." The Leadership Quarterly 27 (3): 44655.

Schmidt, Vivien A. 2010. "Taking Ideas and Discourse Seriously: Explaining Change through Discursive Institutionalism as the Fourth 'New Institutionalism.'" European Political Science Review 2 (1): 1-25.

Schwartz-Shea, Peregrine, and Dvora Yanow. 2012. Interpretive Research Design: Concepts and Processes. New York, NY: Routledge.

Scott, Joan. 1986. "Gender: A Useful Category of Historical Analysis." The American Historical Review 91 (5): 1053-75.

Shepherd, Laura J. 2008. "Power and Authority in the Production of United Nations Security Council Resolution 1325." International Studies Quarterly 52 (2): 383-404.

- - . 2010. "Sex or Gender? Bodies in World Politcs and Why Gender Matters." In Gender Matters in Global Politics: A Feminist Introduction to International Relations, edited by Laura J. Shepherd, 3-16. New York: Routledge.

- - . 2011. "Sex, Security and Superhero(in)es: From 1325 to 1820 and Beyond." International Feminist Journal of Politics 13 (4): 504-21.

- - . 2013. Gender, Violence and Popular Culture: Telling Stories. London: Routledge.

Shinozaki, Kyoko. 2014. "Career Strategies and Spatial Mobility among Skilled Migrants in Germany: The Role of Gender in the Work-Family Interaction." Tijdschrift Voor Economische En Social Geografie 105 (5): 526-41.

Sinclair, Amanda. 2005. "Body and Management Pedagogy." Gender, Work and Organization 12 (1): 89-104.

Sjoberg, Laura. 2011. "Gender, the State, and War Redux: Feminist International Relations across the 'Levels of Analysis.'” International Relations 25 (1): 10834. 
Skard, Torild. 2008. "Getting Our History Right: How Were the Equal Rights of Women and Men Included in the Charter of the United Nations." Forum for Development Studies 35 (1): 37-70.

Steans, Jill. 2013. Gender and International Relations: Theory, Practice, Policy. 3rd ed. Cambridge: Polity.

Suganami, Hidemi. 1999a. "Agents, Structures, Narratives." European Journal of International Relations 5 (3): 365-386.

- - . 1999b. "Narrative Explanation and International Relations. Back to Basics." Millennium 37 (2): 327-56.

Sylvester, Christine. 2013. War as Experience: Contributions from International Relations and Feminist Analysis. London: Routledge.

Thomson, Jennifer. 2018. "The Women, Peace, and Security Agenda and Feminist Institutionalism: A Research Agenda." International Studies Review online advance (June). https://doi.org/10.1093/isr/viy052.

Tickner, J. Ann. 1992. Gender in International Relations: Feminist Perspectives on Achieving Global Security. New York: Columbia University Press.

- - . 2001. Gendering World Politics: Issues and Approaches in the Post-Cold War Era. New York: Columbia University Press.

- - . 2006. "Feminism Meets International Relations: Some Methodological Issues." In Feminist Methodologies for International Relations, edited by Brooke A. Ackerly, Maria Stern, and Jacqui True, 1st ed., 19-41. Cambridge, UK ; New York: Cambridge University Press.

True, Jacqui. 2010. "Mainstreaming Gender in International Institutions." In Gender Matters in Global Politics: A Feminist Introduction to International Relations, edited by Laura J. Shepherd, 189-203. New York: Routledge.

UN General Assembly. 2017a. "Improvement in the Status of Women in the United Nations. Report of the Secretary General. UN Document No. A/72/220. Web Annex XIV: Status of Women in the Department of Peacekeeping Operations and Department of Field Support (DPKO/DFS)." http://www.unwomen.org//media/headquarters/attachments/sections/library/publications/2017/statu s-of-women-2017-annex14-status-of-women-in-dpko-and-dfsen.pdf?la=en\&vs=5346.

- - . 2017b. "Improvement in the Status of Women in the United Nations System: Report of the Secretary-General. UN Document No. A/72/220. Web Annex XV: Field Mission Leadership in Peacekeeping and DFS Missions." http://www.unwomen.org/-

/media/headquarters/attachments/sections/library/publications/2017/statu s-of-women-2017-annex15-field-mission-leadership-in-peacekeeping-anddfs-missions-en.pdf?la=en\&vs=5346.

- - . 2017c. "Improvement in the Status of Women in the United Nations System. Report of the Secretary-General. UN Document No. A/72/220."

United Nations. 2016. "Senior Officials of the United Nations and Officers of Equivalent Rank Whose Duty Station Is New York." Protocol and Liaison Service.

Wibben, Annick T. R. 2011. Feminist Security Studies. A Narrative Approach. London: Routledge. 
Wright, Katherine. 2016. "NATO's Adoption of UNSCR 1325 on Women, Peace and Security: Making the Agenda Reality." International Political Science Review 3 (3): 350-61.

Wright, Katherine, and Roberta Guerrina. 2016. "Gendering Normative Power Europe: Lessons of the Women, Peace and Security Agenda." International Affairs 92 (2): 293-312.

Zalewski, Marysia. 2006. "Distracted Reflections on the Production, Narration, and Refusal of Feminist Knowledge in International Relations." In Feminist Methodologies for International Relations, edited by Brooke A. Ackerly, Maria Stern, and Jacqui True, 1st ed., 42-61. Cambridge, UK ; New York: Cambridge University Press.

- - . 2010. "Feminist International Relations: Making Sense..." In Gender Matters in Global Politics: A Feminist Introduction to International Relations, edited by Laura J. Shepherd, 28-43. New York: Routledge. 